\title{
ARTICLE
}

\section{Evidence of Countergradient Variation in Growth of Spotted Gars from Core and Peripheral Populations}

\author{
Solomon R. David* \\ Daniel P. Haerther Center for Conservation and Research, John G. Shedd Aquarium, \\ 1200 South Lake Shore Drive, Chicago, Illinois 60605, USA
}

Richard S. Kik IV

Belle Isle Conservancy, 8109 East Jefferson, Detroit, Michigan 48214, USA

\author{
James S. Diana \\ School of Natural Resources and Environment, University of Michigan, 440 Church Street, Ann Arbor, \\ Michigan 48109-1041, USA
}

\section{Edward S. Rutherford}

National Oceanic and Atmospheric Administration, Great Lakes Environmental Research Laboratory, 4840 South State Road, Ann Arbor, Michigan 48108-9719, USA

\author{
Michael J. Wiley \\ School of Natural Resources and Environment, University of Michigan, 440 Church Street, Ann Arbor, \\ Michigan 48109-1041, USA
}

\begin{abstract}
Peripheral populations occupy the edge of a species' range and may exhibit adaptations to potentially "harsher" marginal environments compared with core populations. The peripheral population of Spotted Gar Lepisosteus oculatus in the Great Lakes basin represents the northern edge of the species' range and is completely disjunct from the core Mississippi River basin population. Age-0 Spotted Gars from the peripheral population experience a growing season approximately half that of the core population but reach similar sizes by winter, suggesting potential for countergradient variation in growth, i.e. an evolutionary response to an environmental gradient such as latitude to compensate for the usual phenotypic effect of that gradient. In this study we used two common garden experiments to investigate potential countergradient variation in growth of young-of-year Spotted Gars from peripheral populations in comparison with those from core populations. Our first experiment showed that in a common environment under temperatures within the first growing season $\left(22-24^{\circ} \mathrm{C}\right)$, Spotted Gars from the peripheral population had significantly higher growth rates than those from the core population. Final Spotted Gar weight-length ratio was also higher in the peripheral versus core population. In our second experiment, under three temperature treatments $\left(16,23\right.$, and $\left.30^{\circ} \mathrm{C}\right)$, maximum growth occurred at the highest temperature, whereas growth ceased at the lowest temperature for both populations. These results suggest that important genetic and physiological differences could exist between the two population groups, consistent with countergradient variation. Our findings indicate that countergradient growth variation can occur even in relatively slowly evolving fishes, such as gars (family Lepisosteidae), and that protection of peripheral populations should be a key component of fish conservation planning.
\end{abstract}

\footnotetext{
*Corresponding author: sdavid@ sheddaquarium.org
}

Received December 14, 2014; accepted April 6, 2015 
The loss of biodiversity is a global crisis threatening all major habitats and ecological scales (United Nations 1992). The loss of local species populations can have cascading effects, influencing entire ecosystems and disrupting important ecosystem services (Garner et al. 2005; Hooper et al. 2005; Helfman 2007). Furthermore, the relationship between species and ecosystem services is mainly a function of the size of local populations, not just the overall existence of species themselves (Luck et al. 2003). Therefore, conserving distinct local populations (population diversity; Luck et al. 2003) is an essential part of the conservation of biodiversity.

Peripheral or "fringe" populations occupy the edge of a species' range and are considered to be exceptionally important in terms of a species' ecology, biogeography, evolution, and conservation (Scudder 1989; Lesica and Allendorf 1995; Latta 2003). Peripheral populations often persist under environmental conditions distinct from those experienced by the species' central or "core" populations and therefore may exhibit specific genetic and phenotypic adaptations to potentially "harsher" environments (Yakimowski and Eckert 2007). Due to small size, fragmentation, or complete disjunction, many peripheral populations have low recolonization potential and therefore are more susceptible to environmental perturbations, as well as extinction (Lesica and Allendorf 1995; Channell and Lomolino 2000; Wisely et al. 2004). Peripheral populations also often experience very low gene flow and high degrees of genetic drift, leading to further divergence from core populations (Jones et al. 2001; Lammi et al. 2001; Johannesson and Andre 2006).

Because of differing environmental conditions related to geographical factors such as latitude, populations may also exhibit different reaction norms, which in turn affect various life history characteristics, such as size and age at maturity, growth rate, or fecundity (Stearns and Koella 1986; Berrigan and Koella 1994; Power and McKinley 1997; Munch et al. 2003; Heibo et al. 2005; Slaughter et al. 2008). Such latitudinal variation in life history characteristics has been observed in many different taxa including plants (Yakimowski and Eckert 2007), mammals (Kyle and Strobeck 2002), reptiles (Wilson and Cooke 2004), invertebrates (Lee et al. 1998; Lardies et al. 2004), and fish (Kynard 1997; Yamahira and Conover 2002; Foster and Vincent 2004). Coupled with genetic drift and low gene flow, these latitudinal variations in life history characteristics may contribute to evolutionary divergence between peripheral and core populations. For all these reasons, speciation is likely to take place in peripheral populations, making them evolutionarily important (Lesica and Allendorf 1995). Conserving extant peripheral populations is therefore a unique and integral component of conserving global biodiversity (Lammi et al. 2001; Johannesson and Andre 2006).

Peripheral populations may also exhibit different growth rates, often associated with the length of the growing season (characterized by warmer temperatures), which varies at different latitudes (Slaughter et al. 2004). Variation in growth rate, or capacity for growth, in a species that occurs across a range of latitudes may provide evidence for countergradient variation (Conover 1990). Countergradient compensatory growth occurs when the average effects of genetic and environmental influences oppose each other across an environmental gradient (Conover and Schultz 1995). Countergradient variation theory holds that some populations of a species at higher latitudes with shorter growing seasons have a higher capacity for growth than individuals from populations at lower latitudes (Conover and Present 1990; Yamahira and Conover 2002). Higher growth capacity at higher latitudes would contribute to increased overwinter survival and may result in a relatively similar size at the end of the growing season for individuals from higher- and lower-latitude populations (Hurst 2007; see Conover et al. 2009 for a full review of countergradient variation).

Countergradient variation has been identified in a number of freshwater and marine fishes, such as Striped Bass Morone saxatilis, Mummichog Fundulus heteroclitus, American Shad Alosa sapidissima (Conover 1990), Lake Sturgeon Acipenser fulvescens (Power and McKinley 1997), and Atlantic Cod Gadus morhua (Marcil et al. 2006). However, not all fishes exhibit this trait; Pumpkinseed Lepomis gibbosus, sticklebacks Gasterosteus spp., and Guppy Poecilia reticulata show cogradient variation, for which genetic and environmental influences on phenotype are aligned across a gradient (Conover et al. 2009). Furthermore, tradeoffs with the higher capacity for growth may occur in the form of a reduced swimming ability and higher risk of predation (Billerbeck et al. 2001; Conover et al. 2005). Countergradient variation in growth may therefore result in both genetic and morphological differences between peripheral and core populations, further enhancing the conservation value of peripheral populations.

Although relatively common in the lower Mississippi River drainage and other areas of the southern United States, the Spotted Gar Lepisosteus oculatus is poorly studied and its ecology and status are comparatively unknown in the Great Lakes Basin. The Spotted Gar is a species of greatest conservation need in the state of Michigan (Michigan Department of Natural Resources 2005), and there have been no previous studies focusing on the species within the state. The Spotted Gar is a native top-level predator (primarily piscivorous), preferring clear vegetated waters, particularly wetlands and floodplain habitat of lakes and large rivers (Suttkus 1963; Trautman 1981; Page and Burr 1991). The species is an important component of native food webs, but is threatened, or in some cases has completely disappeared, due to degradation and loss of habitat in its range (Trautman 1981; Carman 2002). Because of its specific habitat preferences, the Spotted Gar may also be useful as an environmental indicator of aquatic ecosystem health (USEPA 2007).

The Great Lakes population of Spotted Gars represents the northern edge of the species' range and is also completely 


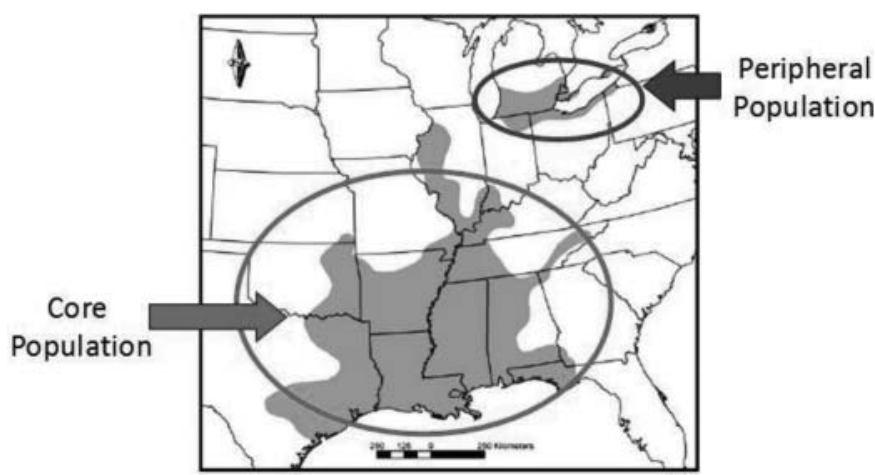

FIGURE 1. Distribution of core and peripheral populations of the Spotted Gar. Note the disjunction between the populations. Modified from Page and Burr (1991).

disjunct from the southern U.S. population (Figure 1; Page and Burr 1991). The species dates back to the early Eocene (4855 million years ago; Wiley 1976; Grande 2010) but arrived in the Great Lakes region relatively recently, approximately 8,000 years ago, when water temperatures began to rise following the Wisconsinan Glaciation (Bailey and Smith 1981; Hubbs et al. 2004). Spotted Gars in the Great Lakes region are separated by a large latitudinal distance from the core population (approximately 1,231 km between population centers), and the average length of the growing season is 50\% shorter, approximately $111 \mathrm{~d}$ in the Great Lakes region compared with $229 \mathrm{~d}$ in the southern United States (NOAA National Climate Data Center 2011). Because of the large latitudinal distance and differences in the length of the growing season, variations in population life history characteristics, such as growth rate, might be expected. These disjunct Spotted Gar populations therefore provide an interesting opportunity to investigate countergradient differences between peripheral and core populations.

Countergradient variation, or more generally latitudinal variation in growth, has not been studied in gars (family Lepisosteidae), and the disjunct distribution and ancient ancestry of the Spotted Gar makes it a unique model species for the investigation of this phenomenon. To explore the potential differences in core and peripheral gar populations in the context of countergradient variation theory, we compared growth rates for the first growing season between core and peripheral populations of the Spotted Gar. Our primary objective was to investigate differences in life history patterns, specifically growth rate in the first growing season, between the Great Lakes (peripheral) and southern United States (core) populations of Spotted Gars using common garden experiments. Our second objective was to determine whether any potential variation in growth rate might be explained by countergradient variation theory. We hypothesized that Spotted Gars from the northern peripheral population would exhibit a faster growth rate and higher capacity for growth at all temperatures compared with Spotted Gars from the core population.

\section{METHODS}

Spotted Gars were acquired from two major sources to represent the core and peripheral populations. Core population representatives were collected by colleagues at Nicholls State University (Thibodaux, Louisiana) in late spring 2009 from several localities in southeastern Louisiana using experimental gill nets, and peripheral population representatives were acquired from several inland lakes in southern Michigan. Fish from Louisiana were the progeny of wild-caught individuals from two localities in the Barataria estuary system (Bayou Chevreuil and Golden Ranch) and one locality in the Terrebone estuary system (Chacahoula Swamp) collected in March-April 2009. Individuals from the core populations were intermixed in order to reduce potential genetic bias from a single locality, and the same was done for individuals from peripheral populations. Adult fish from all core populations were maintained together in an indoor tank, and spawning was induced at $21^{\circ} \mathrm{C}$ using Ovaprim (Western Chemical) injections at a concentration of $0.5 \mathrm{~mL} / \mathrm{kg}$ body weight. Ovaprim was introduced via intramuscular injection near the anterior base of the dorsal fin, and spawning occurred within 24-48 h of injection. Viable embryos from this spawning event were then collected from the tank, and approximately 150 specimens were shipped overnight to the University of Michigan.

Adult peripheral population representatives were collected in May 2009 from five different inland lake localities in southern Michigan using a boom electrofishing boat. Marble and East Long lakes are part of the St. Joseph River watershed, and Round, Carpenter, and Sugarloaf lakes are part of the Grand River watershed. Adults from peripheral populations were maintained together in an indoor tank similar to that of core population fish. Spawning was similarly induced using Ovaprim but was not as successful; therefore, several adult fish were stripped of milt and eggs to create approximately 200 embryos. In tables and figures, Spotted Gars from the core population will be referred to as Louisiana (LA) fish and those from the peripheral population as Michigan (MI) fish.

Embryos from both populations were raised in separate $38-\mathrm{L}$ aquaria using aeration and daily $50 \%$ water changes to maintain water quality. A $25-\mathrm{W}$ heater was used to maintain consistent temperature $\left(21-23^{\circ} \mathrm{C}\right)$ during the incubation period, as well as after hatching. Sac-fry and free-swimming larvae were maintained in multiple aquaria separated into core or peripheral populations. Once larvae were zooplanktivorous, they were further separated into three aquaria per population to better maintain water quality. Zooplanktivorous larvae were first fed small daphnia Daphnia spp. and then larger adult brine shrimp Artemia spp. Larvae were fed two to three times a day to maintain a constant supply of food. Upon converting to piscivory, larvae from both populations were fed small $(3.0-\mathrm{cm})$ Fathead Minnows Pimephales promelas. Larvae were further separated roughly based on size into three aquaria per population to reduce cannibalism. Due to the limited supply of larvae and the concern of stressrelated mortality due to handling, early life stage fish (sac-fry 
and zooplanktivorous stages, approximately 0-60 d) were not formally measured; length at hatch was estimated from measuring mortalities and photographs of live individuals. To estimate early life growth rates during the period from 60 to $100 \mathrm{~d}$ after hatch (DAH) preceding experiment 1, 30 individuals from each population were randomly selected weekly for measurements of length $(0.1 \mathrm{~cm})$ and weight $(0.1 \mathrm{~g})$. Mean growth rates $(\mathrm{cm} / \mathrm{d}$ and $\mathrm{g} / \mathrm{d}$ ) were then calculated for each population. Once juvenile Spotted Gars were regularly consuming medium-sized (4.5$6.0 \mathrm{~cm}$; size range used in experiments) Fathead Minnows, individuals were randomly selected from each population and placed into experimental aquaria. All selected individuals were acclimated to experimental aquaria for $4-5 \mathrm{~d}$ prior to the start of experiment 1. Additional individuals were maintained in separate aquaria (based on population) as replacements if needed and for experiment 2.

Experiment 1.-To investigate the potential differences in growth rate under identical temperature and rations, $2075-\mathrm{L}$ aquaria were used to house age-0 Spotted Gars from both populations ( $N=30$ fish from each population). Each aquarium was divided equally into three compartments using thin fiberglass screening, which allowed the passage of water but not other fish. Each compartment housed 1 Spotted Gar (3 per aquarium for a total of 60 Spotted Gars). Each aquarium also contained an airpump-operated sponge filter to maintain water quality and a $50-\mathrm{W}$ heater to maintain a consistent temperature of $22-24^{\circ} \mathrm{C}$. The temperature range was selected based on the mean temperatures experienced during the growing season of both populations (Redmond 1964; Echelle and Riggs 1972; Simon and Wallus 1989; Simon and Tyberghein 1991; S.R.D., personal observation). To further maintain water quality, $50 \%$ of the water was changed weekly for each tank, with waste material removed via siphon. Overhead fluorescent lights on electronic timers were used to maintain a consistent 12-h light and 12-h dark photoperiod during the experiment. Individual Spotted Gars were fed Fathead Minnows at near-maximum ration, based on observed (estimated) consumption during the acclimation period, for the duration of the experiment: $62 \mathrm{~d}$ for core fish and $63 \mathrm{~d}$ for peripheral fish. To maintain near-maximum ration, a small group of Fathead Minnows (approximately 5.0-7.0 g total mass) was supplied daily in each experimental compartment; consumed minnows were replaced and dead minnows were removed to prevent deterioration of water quality. Consumption was not formally recorded but assumed to be equivalent between populations.

Individual Spotted Gars were removed from the compartments to measure length and weight weekly, as well as at the beginning and end of the experimental period. Mean length and weight were used to determine the increase in size $(\mathrm{cm} / \mathrm{d}$ and $g / d$ ) over the experimental period. One-way analysis of variance (ANOVA) was used to test for significant differences in initial and final mean length and weight for both populations. Analysis of covariance (ANCOVA), with population and DAH as fixed factors, was used to determine significant differences in growth rates between populations, if any. We assumed a linear model for growth during the experimental period for both populations of Spotted Gars. The increase in length and weight for each population was plotted versus time (DAH or days of experiment) and analyzed using linear regression to generate growth models. Length-weight relationships were also analyzed (ANOVA, ANCOVA; $P<0.05$ ) and used as a proxy for comparing energy storage between populations.

Experiment 2.-To investigate potential differences in growth rate between populations at different temperatures, Spotted Gars from both populations were divided into three temperature treatments; 16,23 , and $30^{\circ} \mathrm{C}$, for a total of six groups (one peripheral group and one core group per temperature treatment). Each group was comprised of 6 fish, for a total of 36 fish in the experiment. Fish were randomly selected from both the individuals used in experiment 1 and the additional individuals and were all reared under the same temperature $\left(23^{\circ} \mathrm{C}\right)$ and feeding regime (near-maximum ration) for at least $30 \mathrm{~d}$ prior to beginning the experiment. Due to limits in replication because of the low numbers of available fish and tanks (only one replicate of six fish for each population per temperature treatment), primarily descriptive statistics were used to analyze experiment 2 .

Each group of Spotted Gars was placed in a 190-L fiberglass tank containing a stand pipe connected to a large recirculating system for constant water filtration. Temperature was maintained using $75-\mathrm{W}$ heaters in the control and treatment group tanks and was monitored daily. All groups were acclimated to respective temperature treatments for at least $7 \mathrm{~d}$ prior to beginning the experiment. Spotted Gars in all tanks were supplied with Fathead Minnows at near-maximum ration similar to experiment 1 (adjusted for six fish per tank); specific consumption rates were not measured but were assumed to be equivalent between populations for each treatment. Photoperiod was maintained at $12 \mathrm{~h}$ light : $12 \mathrm{~h}$ dark. Within each tank individual fish were identified by a single fin clip from the right or left pectoral fin, right or left pelvic fin, or anal fin or by no fin clip. Marked fins were reclipped as necessary (due to fin regeneration) on measurement days over the course of the experiment. Length and weight of all fish were measured at the beginning of the experiment, as well as weekly for 5 weeks. The total duration of the experiment was $42 \mathrm{~d}$. Mean length and weight were determined weekly for both populations in each treatment, and growth rate was calculated as in experiment 1 .

All statistical analyses were carried out using JMP (2001) software with significance levels set at $\alpha=0.05$.

\section{RESULTS}

Eggs from both populations hatched 6-7 d after fertilization. Hatching success was $70-80 \%$ for both populations, and newly hatched larvae were approximately $1.0 \mathrm{~cm}$ in length and weighed approximately $0.5 \mathrm{~g}$. Larval Spotted 
Gars absorbed their yolk sacs by 6-7 DAH and began feeding on Daphnia and Artemia. Juveniles from both populations began eating small Fathead Minnows at 35-40 DAH.

The growth rate was similar between populations for length but was significantly higher for weight during early life (ANCOVA: sum of squares $=67.84, F$-ratio $=12.17, \mathrm{df}=1$, $P<0.01)$ for core Spotted Gars than for peripheral Spotted Gars held at $23^{\circ} \mathrm{C}$ (Figures 2, 3). Length and weight regression models explained 96-99\% of the variation in the data. Although both groups of fish were of similar age when switching to piscivory and acclimating to experimental aquaria, peripheral fish were significantly smaller than core fish at the beginning of experiment 1 (one-way ANOVA: $P<0.05$; Table 1). The final length and weight of peripheral fish, however, were significantly greater than for core fish (ANOVA: $P<0.05)$. Growth rates and least-squares mean lengths and weights of peripheral Spotted Gars (mean $\pm 1 \mathrm{SE}$, length $=$ $17.40 \pm 0.03 \mathrm{~cm}$, weight $=15.40 \pm 0.28 \mathrm{~g}$ ) were significantly greater than those of core Spotted Gars $(17.10 \pm 0.03 \mathrm{~cm}$, $14.32 \pm 0.34 \mathrm{~g}$; ANCOVA: $P<0.01$; Table 2 ). Linear regression models of growth rates for both populations explained 97-99\% of the variation in the data (Figures 4,5 ).

At the beginning of experiment 1, peripheral fish had a significantly lower weight per unit length than core fish. By the end of experiment 1, however, peripheral fish had a significantly higher weight at length than core fish. Linear regression analysis and ANCOVA indicated that the change in weightlength ratios was significantly different between peripheral (higher rate) and core fish (lower rate) over the course of experiment 1 (Figure 6). Although consumption was not formally recorded, fish from both populations typically consumed their allotted ration on a daily basis during the experimental period.

In experiment 2, the ending size (length and weight) and growth rates of Spotted Gars across all temperature treatments were lowest at $16^{\circ} \mathrm{C}$, higher at $23^{\circ} \mathrm{C}$, and highest at $30^{\circ} \mathrm{C}$ (Table 3; Figure 7). At $16^{\circ} \mathrm{C}$, the coolest treatment, fish from both populations exhibited very small increases in length (peripheral fish $=0.02 \mathrm{~cm}$, core fish $=0.10 \mathrm{~cm}$ ) and decreases in weight (peripheral fish $=-1.18 \mathrm{~g}$, core fish $=-0.38 \mathrm{~g}$ ) over the 42-d period. Clipped fins (used to identify individual fish) did not regenerate and visually estimated consumption of Fathead Minnows was very low compared with the other temperature treatments (i.e., the daily ration of minnows was not fully consumed). In contrast, fish in the $23^{\circ} \mathrm{C}$ and $30^{\circ} \mathrm{C}$ treatments required frequent reclipping of marked fins, as well as much more frequent replacement of Fathead Minnows. As in experiment 1 , fish from both populations typically consumed

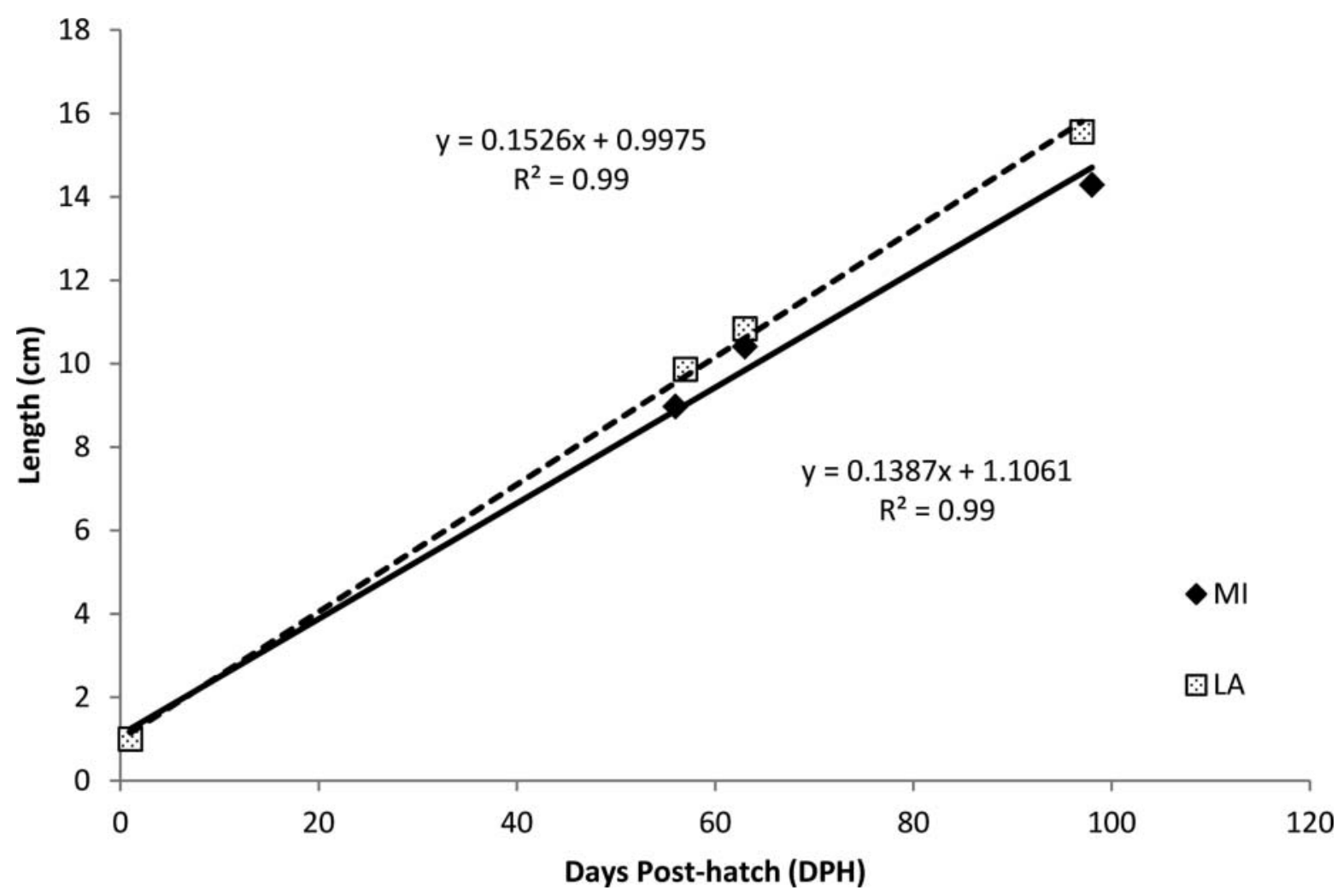

FIGURE 2. Comparison of early life stage (period prior to the start of experiment 1) length at age of Spotted Gars from core (LA) and peripheral (MI) populations that were held at $23^{\circ} \mathrm{C}(N=30 \mathrm{fish} /$ population). Larval fish from both populations hatched at approximately $1.0 \mathrm{~cm}$ in length. Linear regression models (dashed line $=\mathrm{LA}$, solid line $=\mathrm{MI}$ ) and $R^{2}$-values were also calculated. 


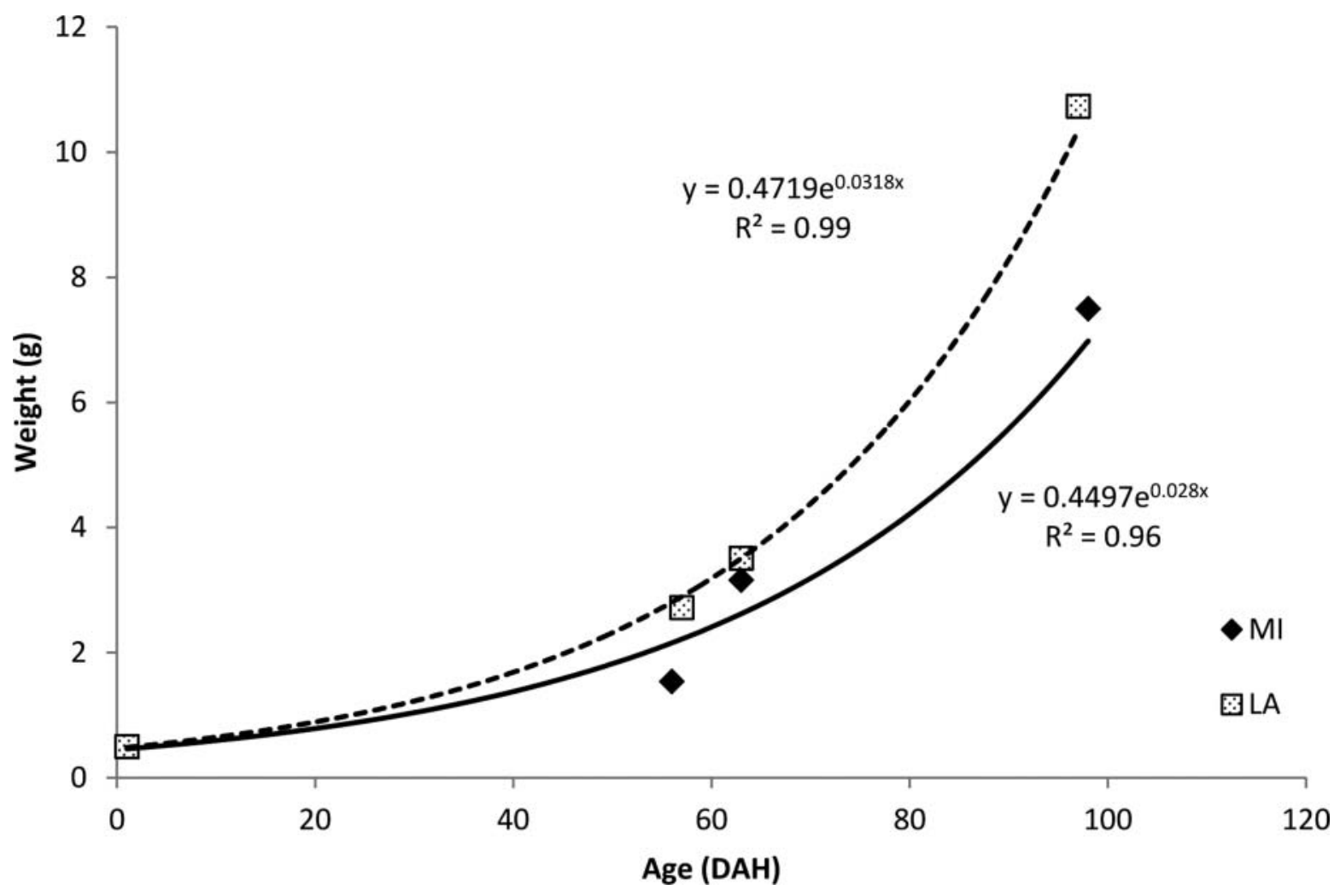

FIGURE 3. Comparison of early life stage (period prior to the start of experiment 1) weight at age of Spotted Gars from core (LA) and peripheral (MI) populations that were held at $23^{\circ} \mathrm{C}(N=30 \mathrm{fish} /$ population). Larval fish from both populations hatched at approximately $0.5 \mathrm{~g}$. Exponential regression models (dashed line $=\mathrm{LA}$, solid line $=\mathrm{MI})$ and $R^{2}$-values were also calculated; $\mathrm{DAH}=$ days after hatch.

their allotted ration on a daily basis during the experimental period.

The peripheral fish in both the $23^{\circ} \mathrm{C}$ and $30^{\circ} \mathrm{C}$ treatments grew faster and larger than the core fish (Figure 8). Maximum growth for both groups occurred at the highest temperature

TABLE 1. Mean length $(\mathrm{cm})$ and weight $(\mathrm{g})$ at initiation and completion of experiment 1 , along with total growth (final length or weight - initial length or weight), growth rate ( $\mathrm{cm} /$ day or g/day), and descriptive statistics for core (LA) and peripheral (MI) populations of Spotted Gars $(N=30$ fish/population). Experimental durations were 62 (LA) and 63 (MI) days.

\begin{tabular}{|c|c|c|c|c|c|}
\hline \multirow[b]{3}{*}{ Measurements } & \multicolumn{2}{|c|}{ Population } & \multirow{2}{*}{\multicolumn{3}{|c|}{ ANOVA }} \\
\hline & MI & LA & & & \\
\hline & Mean SD & Mean SD & df & $F$-Ratio & $P$-Value \\
\hline Initial length & 14.291 .85 & 15.561 .55 & 1,58 & 8.36 & $<0.01$ \\
\hline Final length & 20.061 .64 & 18.241 .45 & 1,58 & 20.57 & $<0.01$ \\
\hline Total growth & 5.77 & 2.68 & & & \\
\hline Growth rate & 0.09 & 0.04 & & & \\
\hline Initial weight & 7.503 .01 & 10.743 .21 & 1,58 & 16.23 & $<0.01$ \\
\hline Final weight & 24.096 .84 & 17.534 .12 & 1,58 & 20.26 & $<0.01$ \\
\hline Total growth & 16.59 & 6.79 & & & \\
\hline Growth rate & 0.26 & 0.11 & & & \\
\hline
\end{tabular}

treatment, while the $16^{\circ} \mathrm{C}$ treatment appeared to be at or near the point at which growth ceased in both populations of Spotted Gars.

\section{DISCUSSION}

We hypothesized that Spotted Gars from two disjunct population segments would exhibit latitudinal compensation in growth similar to several other fish species (Conover et al. 2009) and that under common environmental conditions fish from a higher latitude would grow faster than those from a lower latitude. Our experiments showed that in a common environment simulating periods within the first growing season, the Spotted Gars from the peripheral population had a significantly higher growth rate than those from the core population, suggesting that important genetic and physiological differences exist between the two population groups. Although the lack of treatment replication limits the statistical analyses of experiment 2, results suggest that peripheral Spotted Gars achieved a higher growth rate than core population fish even at warmer temperatures and that both populations had similar thermal minima for growth. Both experiments taken together provide strong evidence for countergradient variation in the growth rate of Spotted Gars. 
TABLE 2. Results of $F$-tests for the equality of slopes from length-day after hatch (DAH) and weight-DAH relationships for Spotted Gars between peripheral and core populations. The degrees of freedom (df), sum of squares (SS), $F$-ratios, and $P$-values are also reported.

\begin{tabular}{lllrrr}
\hline Variable & \multicolumn{1}{c}{ Source } & df & SS & $F$-ratio & $P$-value \\
\hline Length & DAH & 1 & 26.94 & $3,992.6$ & $<0.01$ \\
& Population & 1 & 0.32 & 46.94 & $<0.01$ \\
Weight & DAH $\times$ population & 1 & 3.92 & 580.93 & $<0.01$ \\
& DAH & 1 & 220.19 & 317.66 & $<0.01$ \\
& Population & 1 & 4.25 & 6.13 & $<0.01$ \\
Weight $:$ length & DAH $\times$ population & 1 & 46.39 & 66.93 & $<0.01$ \\
& Length & 1 & $11,306.69$ & $3,921.19$ & $<0.01$ \\
& Population & 1 & 78.74 & 27.31 & $<0.01$ \\
& Length $\times$ population & 1 & 38.74 & 38.75 & $<0.01$ \\
\hline
\end{tabular}

As in the Atlantic Silverside Menidia menidia, the model species used to investigate countergradient variation in growth by Conover and Present (1990) (see also Conover 1992; Present and Conover 1992), Spotted Gars begin spawning at approximately the same temperature $\left(23^{\circ} \mathrm{C}\right)$ but later in the year with increasing latitude (Redmond 1964; Holt 1973; Trautman 1981; Becker 1983; Snedden 1999). Conover (1990) also noted that later initiation of spawning and earlier onset of winter resulted in a much shorter growing season at higher latitudes. Although the length of the growing season decreases as latitude increases, the mean size at the end of the first growing season does not decrease with increasing latitude for several fish species (Conover et al. 2009). Therefore populations of these species at higher latitudes are able to compensate for shorter growing seasons by evolving faster growth rates than lower-latitude populations (Conover 1992).

Observed growth rates for Spotted Gars were higher in the peripheral population than in the core population over a simulated growing season (experiment 1). This result provides further

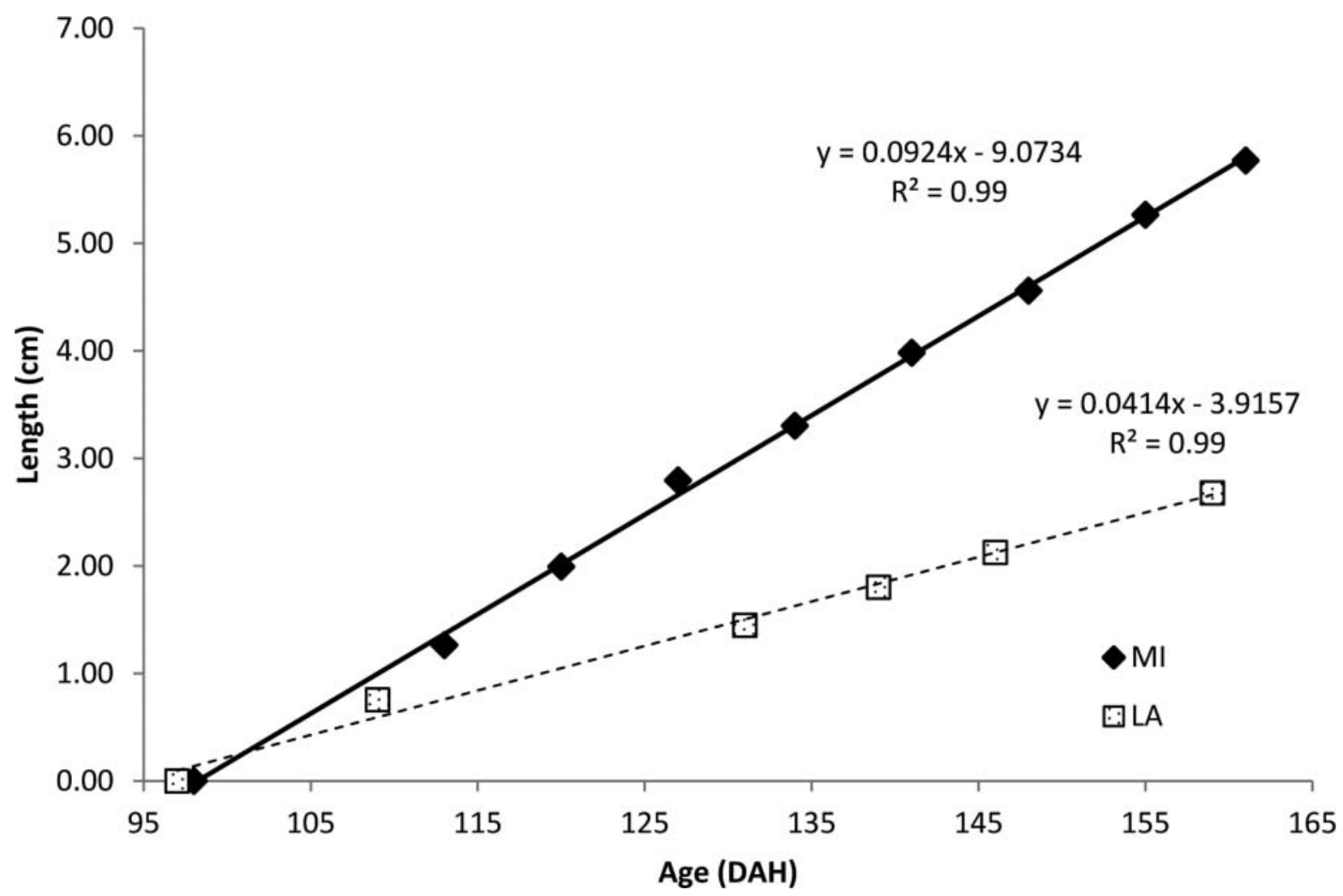

FIGURE 4. Increase in length over time for Spotted Gars from core (LA) and peripheral (MI) populations that were held at $23^{\circ} \mathrm{C}$ in experiment 1 $(N=30$ fish/population). Linear regression models (dashed line $=\mathrm{LA}$, solid line $=\mathrm{MI})$ and $R^{2}$-values were also calculated; DAH $=$ days after hatch 


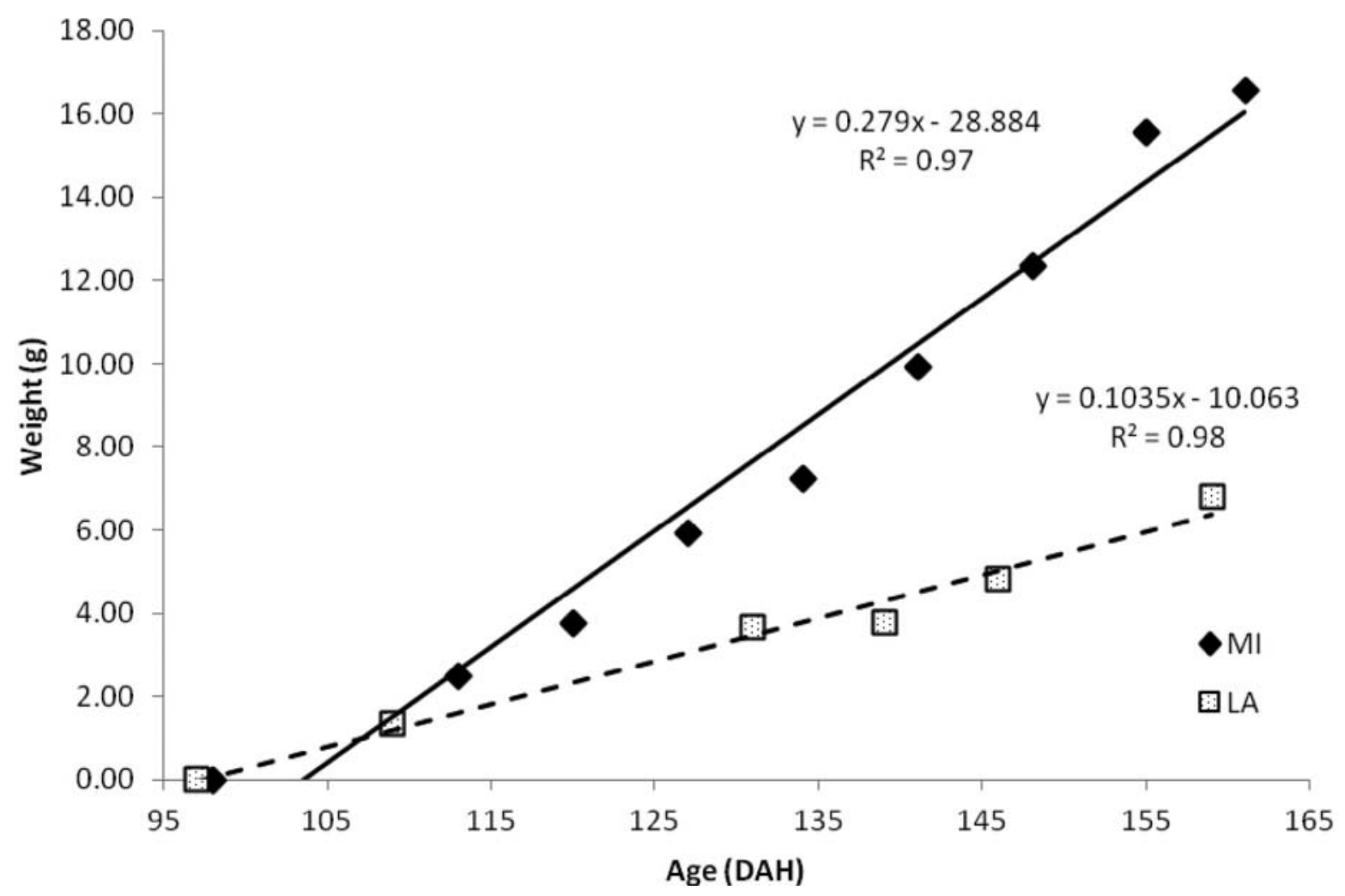

FIGURE 5. Increase in weight over time for Spotted Gars from core (LA) and peripheral (MI) populations that were held at $23^{\circ} \mathrm{C}$ in experiment $1(N=30$ fish/population). Linear regression models (dashed line $=\mathrm{LA}$, solid line $=\mathrm{MI}$ ) and $R^{2}$-values were also calculated; DAH $=$ days after hatch.

support of countergradient variation when experimental growth rates are applied to the estimated respective length of the growing season, resulting in larger peripheral population fish or similar-sized individuals between the populations (peripheral: $0.09 \mathrm{~cm} / \mathrm{d} \times 111 \mathrm{~d}=9.99 \mathrm{~cm}, 0.26 \mathrm{~g} / \mathrm{d} \times 111 \mathrm{~d}=28.86 \mathrm{~g}$; core: $0.04 \mathrm{~cm} / \mathrm{d} \times 229 \mathrm{~d}=9.16 \mathrm{~cm}, 0.11 \mathrm{~g} / \mathrm{d} \times 229 \mathrm{~d}=$ $25.19 \mathrm{~g}$ ); albeit this is a very coarse estimate (Conover et al. 2009). Future studies incorporating field-based length-at-age and length-of-growing-season estimates (such as hard structures, older individuals, and thermal opportunity for growth by degreedays; Power and McKinley 1997; David 2012) for multiple populations may further elucidate latitudinal differences in growth rates.

Differences in growth rate may be indicative of other interesting eco-evolutionary dynamics between core and peripheral populations of Spotted Gars (David 2012), such as differences in life history patterns, as well as morphological and genetic variation (Wright et al. 2012; Glass et al., in press). From an evolutionary perspective, our results suggest that rapid adaptation in growth rate has occurred even in relatively slowly evolving fishes, such as gars (Wiley 1976; Conover et al. 2009; Grande 2010; Carlson et al. 2011). The Spotted Gar, a warmwater species, entered the Great Lakes region via connections to the Mississippi River drainage (southern refugium) following the last glaciation no more than 8,000 years ago
(Bailey and Smith 1981; Hocutt and Wiley 1986). Therefore the adaptation of growth rate to the length of the growing season must be a relatively recent evolutionary development. Similarly, Mach et al. (2011) showed that in Atlantic Silversides, another species that expanded northward postglaciation from a single southern refugium, regional adaptation (e.g., countergradient variation) and phenotypic divergence developed since the last glaciation. Using Pacific salmon Oncorhynchus spp., Carlson et al. (2011) showed that shifts in body size due to selection over even a single generation can have large and lasting evolutionary impacts on both species and ecosystems.

The scope of our study was limited to two of several regionally distinct populations (core and peripheral) of Spotted Gars; including more populations in future experiments may provide a better picture of the gradient in growth rate with increasing latitude. Despite this limitation, our study populations did represent a natural break in the distribution of Spotted Gars, in that the species is completely disjunct between the Great Lakes and Mississippi River basins (Page and Burr 1991); therefore, these comparisons are realistic if not comprehensive. The core population does span a greater latitudinal range than the peripheral population (approximately $1,550 \mathrm{~km}$ compared with $220 \mathrm{~km}$ ); therefore, growth rate comparisons among fish from multiple core populations are recommended. 


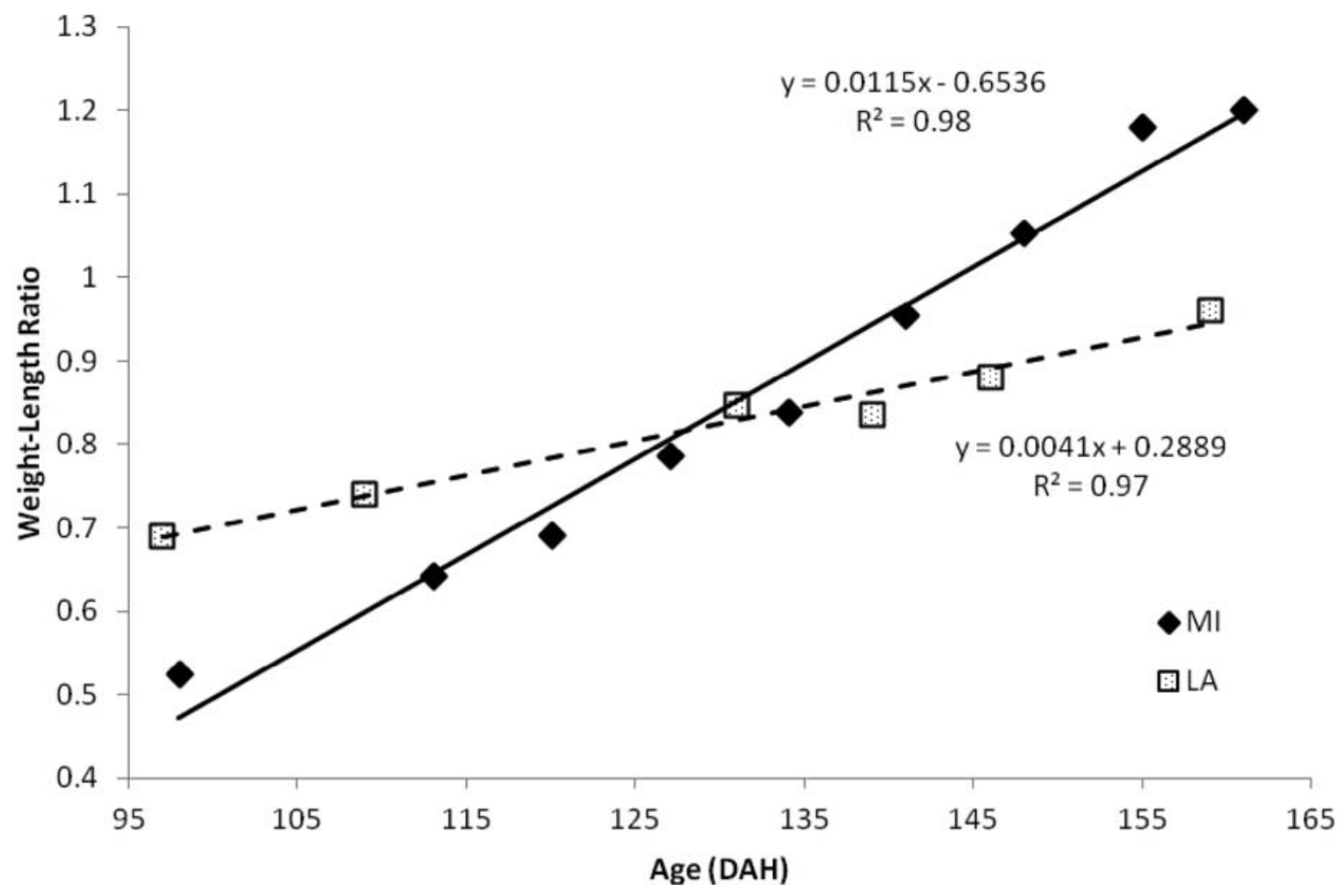

FIGURE 6. Mean weight-length ratios over time for Spotted Gars from the core (LA) and peripheral (MI) populations that were held at $23^{\circ} \mathrm{C}$ in experiment 1 $(N=30$ fish/population). Linear regression models (dashed line $=\mathrm{LA}$, solid line $=\mathrm{MI})$ and $R^{2}$-values were also calculated; DAH $=$ days after hatch.

Detailed measurements of the early life stages preceding piscivory (e.g., zooplanktivorous stage) were not formally made in our experiments; however, the growth rate for weight observed during these early stages was higher in core than in peripheral populations. Once the piscivorous stage was reached, the growth rate was higher in peripheral than in core populations. Mittelbach and Persson (1998) found that growth rates of piscivorous fishes (including gars) greatly increased between the zooplanktivorous and piscivorous stages. Although growth rates were significantly different between populations at early life stages, differences in growth rate were comparatively much greater when Spotted Gars switched to piscivory. Experiments comparing gars at prepiscivorous stages would help clarify early life stage differences between core and peripheral populations.

Our study did not specifically measure consumption rates or ration; however, fish from both populations typically consumed their allotted ration on a daily basis in both experiments (with the exception of the lowest temperature treatment in experiment 2), suggesting that consumption rates were similar between populations in our study. Present and Conover (1992) showed that at excess ration, a higher growth rate in Atlantic Silversides from a higher latitude could be explained by genetic variation in consumption rate and gross growth efficiency compared with a lower-latitude population. We assumed consumption rates to be similar between populations in our experiments; complete consumption of the daily ration by both populations supports this, and higher conversion efficiency and other metabolic rates (Conover and Schultz 1995) may similarly explain differences in Spotted Gar growth rates between core and peripheral populations. To better understand the drivers of the observed differences in growth rate, future studies comparing metabolic rates of peripheral and core Spotted Gars are recommended, as well as exploration of any potential molecular basis.

Although countergradient variation has been observed in a variety of ectotherms, most frequently in fishes, it has not previously been observed in gars. Furthermore, our study is the first to use common garden experiments to test for latitudinal variation in a nonteleost fish, an understudied group in such investigations, often because of their typically late maturation and long generation time (Ferrara 2001; Mendoza Alfaro et al. 2008) compared with teleosts in similar studies (Conover and Present 1990; Schultz et al. 1996; Arendt and Wilson 1997; Power and McKinley 1997; Conover et al. 2009; Baumann and Conover 2011). Our results suggest that countergradient variation may be important in other evolutionarily and economically significant nonteleost species (i.e., lungfishes [subclass Dipnoi], sturgeons [family Acipenseridae], and Alligator Gar Atractosteus spatula). 
TABLE 3. Mean length $(\mathrm{cm})$ and weight $(\mathrm{g})$ at initiation and completion of experiment 2, along with total growth (final length or weight - initial length or weight), growth rate $(\mathrm{cm} /$ day or $\mathrm{g} /$ day), and descriptive statistics for core and peripheral populations of Spotted Gars at three different temperature treatments ( $N=6 \mathrm{fish} /$ population in each treatment). Experimental duration was $42 \mathrm{~d}$.

\begin{tabular}{|c|c|c|c|c|c|}
\hline \multirow[b]{2}{*}{$\begin{array}{l}\text { Experimental } \\
\text { temperature }\left({ }^{\circ} \mathrm{C}\right)\end{array}$} & \multirow[b]{2}{*}{ Measurement } & \multicolumn{2}{|c|}{ Peripheral } & \multicolumn{2}{|c|}{ Core } \\
\hline & & Mean & SD & Mean & SD \\
\hline & & Length & & & \\
\hline \multirow[t]{4}{*}{16} & Initial length & 21.07 & 1.03 & 19.17 & 1.26 \\
\hline & Final length & 21.08 & 0.97 & 19.27 & 1.37 \\
\hline & Total growth & 0.02 & & 0.10 & \\
\hline & Growth rate & $<0.01$ & & $<0.01$ & \\
\hline \multirow[t]{4}{*}{23} & Initial length & 20.75 & 0.82 & 19.85 & 2.70 \\
\hline & Final length & 23.52 & 1.12 & 21.33 & 2.72 \\
\hline & Total growth & 2.77 & & 1.48 & \\
\hline & Growth rate & 0.07 & & 0.04 & \\
\hline \multirow[t]{5}{*}{30} & Initial length & 22.60 & 2.62 & 20.72 & 0.95 \\
\hline & Final length & 25.50 & 1.72 & 23.15 & 1.11 \\
\hline & Total growth & 2.90 & & 2.43 & \\
\hline & Growth rate & 0.07 & & 0.06 & \\
\hline & & Weigh & & & \\
\hline \multirow[t]{4}{*}{16} & Initial weight & 27.73 & 4.73 & 21.77 & 4.92 \\
\hline & Final weight & 26.55 & 4.31 & 21.38 & 5.02 \\
\hline & Total growth & -1.18 & & -0.38 & \\
\hline & Growth rate & -0.03 & & -0.01 & \\
\hline \multirow[t]{4}{*}{23} & Initial weight & 24.63 & 3.26 & 23.73 & 9.82 \\
\hline & Final weight & 37.12 & 6.70 & 30.05 & 13.97 \\
\hline & Total growth & 12.48 & & 6.32 & \\
\hline & Growth rate & 0.30 & & 0.15 & \\
\hline \multirow[t]{4}{*}{30} & Initial weight & 32.50 & 11.60 & 25.27 & 4.48 \\
\hline & Final weight & 51.97 & 10.44 & 36.32 & 6.48 \\
\hline & Total growth & 19.47 & & 11.05 & \\
\hline & Growth rate & 0.46 & & 0.26 & \\
\hline
\end{tabular}

The countergradient variation in the growth of Spotted Gars may also have implications for the species' response to future climate change and to opportunities for range expansion. Using the weak latitudinal temperature gradient of Topsmelt Atherinops affinis as a proxy for the gradual effects of climate change, Baumann and Conover (2011) showed that two species, Atlantic Silversides and Topsmelt, each experiencing very different latitudinal temperature gradients, still exhibited countergradient variation in growth. Their study indicated that ectotherms have evolved growth adaptations to even weak climate gradients and that a poleward migration of genotypes will be a likely result of an increasingly warmer climate. As a warmwater species exhibiting countergradient variation, Spotted Gars would likely successfully increase their range northward with gradual increases in temperature.

Peripheral populations are important in terms of a species' ecology, biogeography, and evolution but also from a conservation perspective (Scudder 1989; Conover et al. 2009).
Because populations of species at the end of their range may be more susceptible to perturbation, identifying these at-risk populations is important (Glass et al., in press). Observed differences (or lack thereof) in the size of individuals across a range of latitudes may help identify at-risk populations. Common garden experiments, coupled with age-growth and genetic analyses could confirm the existence of countergradient variation and unique populations (David 2012). Further, in efforts to restore declining populations of species, individuals are often transplanted from one population to another (Fischer and Lindenmayer 2000); because countergradient variation may not be readily observable, these transplants should be made with caution to avoid the stocking of maladaptive genotypes into new environments (Conover et al. 2009).

Previous studies have shown that in aquatic systems, species at higher trophic levels are at higher risk of extirpation and are more frequently lost than those at lower trophic levels, in part because of their relatively small population sizes 
A. $16^{\circ} \mathrm{C}$
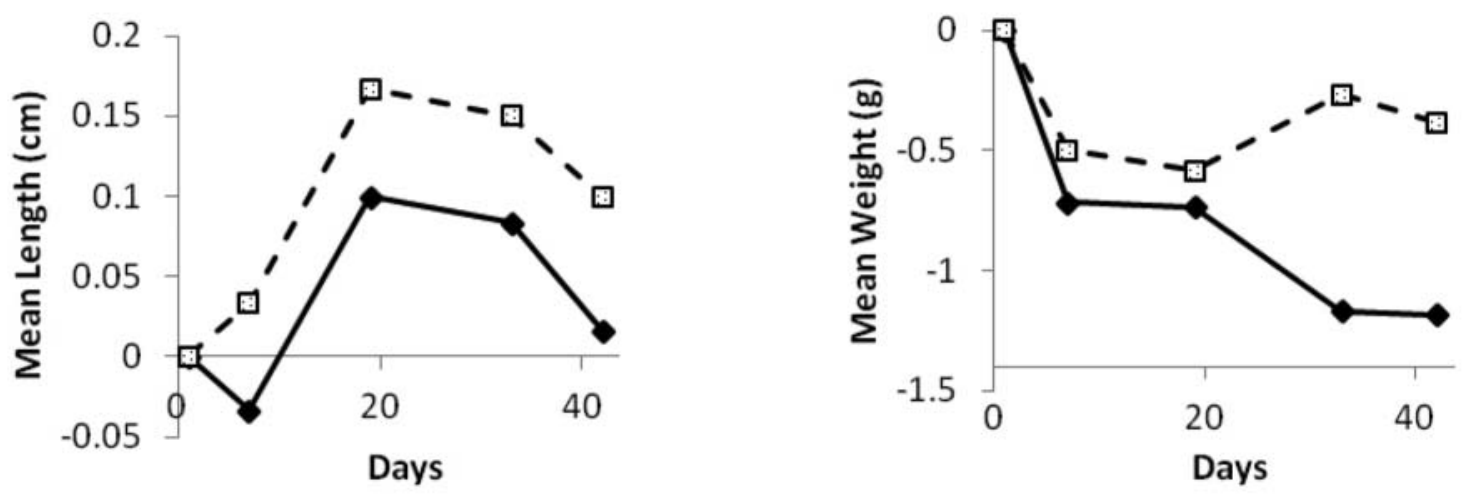

B. $23{ }^{\circ} \mathrm{C}$
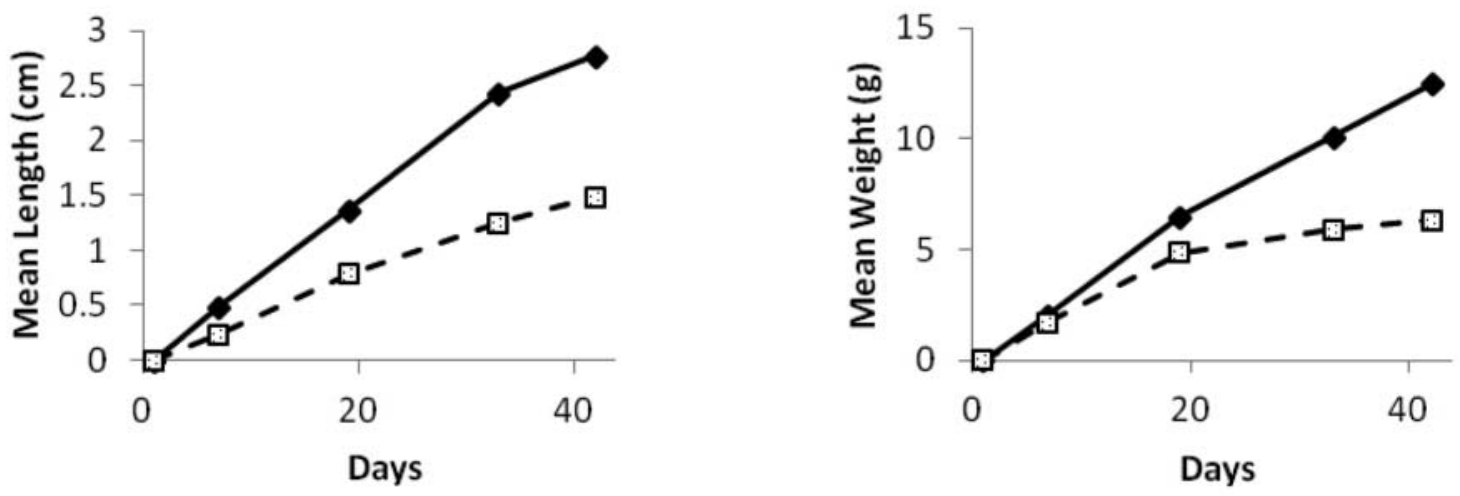

C. $30^{\circ} \mathrm{C}$
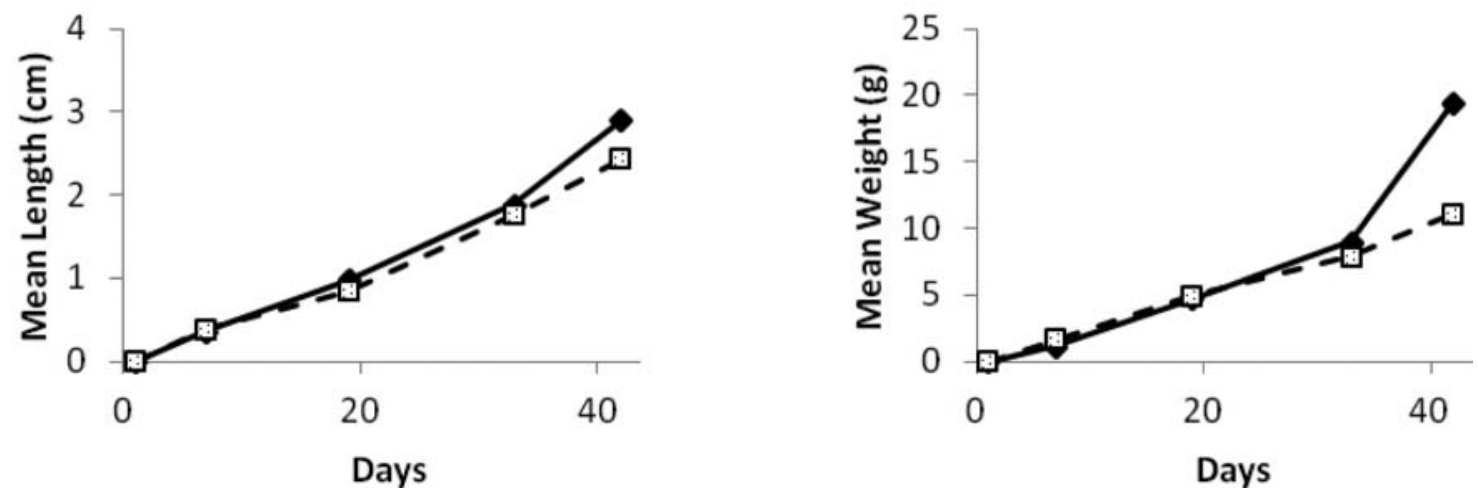

FIGURE 7. Changes in mean length and weight for Spotted Gars from peripheral (solid line) and core (dashed line) populations at three temperature treatments in experiment 2: $(\mathbf{A}) 16^{\circ} \mathrm{C},(\mathbf{B})=23^{\circ} \mathrm{C}$, and $(\mathbf{C})=30^{\circ} \mathrm{C}(N=6$ fish/population in each treatment; experimental duration $=42 \mathrm{~d})$. Note the change in the $y$-axis scale for length and weight among figures.

(Lande 1993; Petchey et al. 2004). Piscivorous fishes, therefore, may be particularly vulnerable amid the ongoing biodiversity crisis. Furthermore, nongame piscivorous species (e.g., gars and Bowfin Amia calva) may be even more at risk due to their poorly studied ecology, their perceived low economic value, and the higher priority given to propagation and management of game species (centrarchids, percids, esocids), with the latter often leading to the destruction of both nongame 

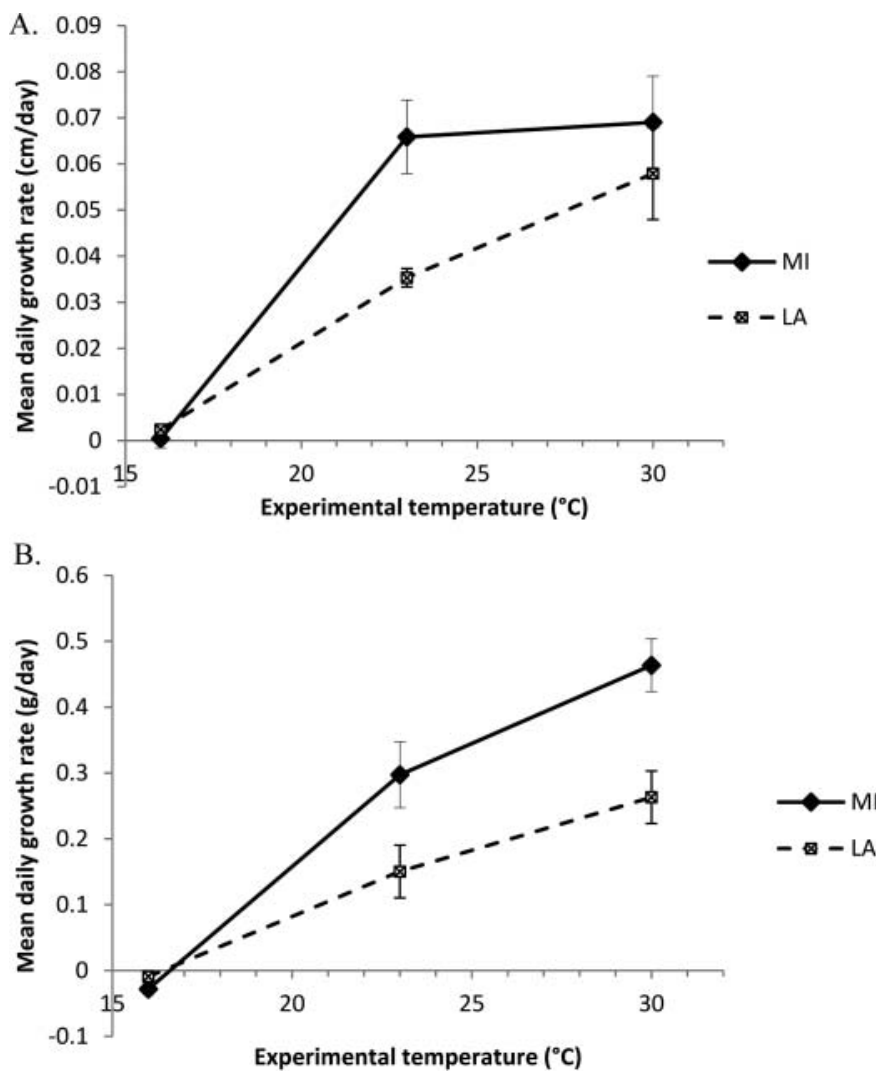

FIGURE 8. Mean daily growth rates for (A) length and (B) weight of Spotted Gars from core (LA) and peripheral (MI) populations at three temperature treatments $\left(16,23\right.$, and $30^{\circ} \mathrm{C} ; N=6 \mathrm{fish} /$ population in each treatment) in experiment 2 (experimental duration $=42 \mathrm{~d}$ ). Error bars indicate $\pm 1 \mathrm{SE}$.

individuals and habitat (Scarnecchia 1992). Our study provides evidence of the unique characteristics of the peripheral population of Spotted Gars and provides more evidence for the general argument that understanding and protecting peripheral populations should be a key component of our programs to conserve natural biodiversity.

\section{ACKNOWLEDGMENTS}

Funding and support for this project were provided in part by the University of Michigan School of Natural Resources and Environment, Michigan Department of Natural Resources, National Oceanic and Atmospheric Administration Great Lakes Environmental Research Laboratory, North American Native Fishes Association, and Fish Doctors Ypsilanti. This is National Oceanic and Atmospheric Administration, Great Lakes Environmental Research Laboratory contribution 1759 . We thank Quenton Fontenot and Allyse Ferrara of Nicholls State University for their expertise on gar spawning, as well as for the gar embryos from core populations. We also thank Brad Utrup, Madison Schaeffer, and Joe Nohner for assistance with common garden experiments and Barry OConnor for manuscript review.

\section{REFERENCES}

Arendt, J. D., and D. S. Wilson. 1997. Optimistic growth: competition and an ontogenetic niche-shift select for rapid growth in Pumpkinseed Sunfish (Lepomis gibbosus). Evolution 51:1946-1954.

Baumann, H., and D. O. Conover. 2011. Adaptation to climate change: contrasting patterns of thermal-reaction-norm evolution in Pacific versus Atlantic silversides. Proceedings of the Royal Society B 278:2265-2273.

Bailey, R. M., and G. R. Smith. 1981. Origin and geography of the fish fauna of the Laurentian Great Lakes basin. Canadian Journal of Fisheries and Aquatic Sciences 38:1539-1561.

Becker, G. C. 1983. Fishes of Wisconsin. University of Wisconsin Press, Madison.

Berrigan, D., and J. C. Koella. 1994. The evolution of reaction norms: simple models for age and size at maturity. Journal of Evolutionary Biology 7:549-566.

Billerbeck, J. M., T. E. Lankford, and D. O. Conover. 2001. Evolution of intrinsic growth and energy acquisition rates: I. tradeoffs with swimming performance in Menidia menidia. Evolution 55:1863-1872.

Carlson, S. M., T. P. Quinn, and A. P. Hendry. 2011. Eco-evolutionary dynamics in Pacific salmon. Heredity 103:438-447.

Carman, S. M. 2002. Special animal abstract for Lepisosteus oculatus (Spotted Gar). Michigan Natural Features Inventory, Lansing.

Channell, R., and M. V. Lomolino. 2000. Trajectories to extinction: spatial dynamics of the contraction of geographical ranges. Journal of Biogeography $27: 169-179$.

Conover, D. O. 1990. The relation between capacity for growth and length of growing season: evidence for and implications of countergradient variation. Transactions of the American Fisheries Society 119:416-430.

Conover, D. O. 1992. Seasonality and the scheduling of life history at different latitudes. Journal of Fish Biology 41:161-178.

Conover, D. O., S. A. Arnott, M. R. Walsh, and S. B. Munch. 2005. Darwinian fishery science: lessons from the Atlantic Silverside (Menidia menidia). Canadian Journal of Fisheries and Aquatic Sciences 62:730-737.

Conover, D. O., T. A. Duffy, and L. A. Hice. 2009. The covariance between genetic and environmental influences across ecological gradients. Annals of the New York Academy of Sciences 1168:100-129.

Conover, D. O., and T. M. C. Present. 1990. Countergradient variation in growth rate: compensation for length of the growing season among Atlantic Silversides from different latitudes. Oecologia 83:316-324.

Conover, D. O., and E. T. Schultz. 1995. Phenotypic similarity and the evolutionary significance of countergradient variation. Trends in Ecology and Evolution 10:248-252.

David, S. R. 2012. Life history, growth, and genetic diversity of the Spotted Gar Lepisosteus oculatus from peripheral and core populations. Doctoral dissertation. University of Michigan, Ann Arbor.

Echelle, A. A., and C. D. Riggs. 1972. Aspects of the early life history of gars (Lepisosteus) in Lake Texoma. Transactions of the American Fisheries Society 101:106-112.

Ferrara, A. M. 2001. Life-history strategy of Lepisosteidae: implications for the conservation and management of Alligator Gar. Doctoral dissertation. Auburn University, Auburn, Alabama.

Fischer, J., and D. B. Lindenmayer. 2000. An assessment of the published results of animal relocations. Biological Conservation 96:1-11.

Foster, S. J., and A. C. J. Vincent. 2004. Life history and ecology of seahorses: implications for conservation and management. Journal of Fish Biology 65:1-61.

Garner, A., J. L. Rachlow, and J. F. Hicks. 2005. Patterns of genetic diversity and its loss in mammalian populations. Conservation Biology 19:1215-1221.

Glass, W. R., R. P. Walter, D. D. Heath, N. E. Mandrak, and L. D. Corkum. In press. Genetic structure and diversity of Spotted Gar (Lepisosteus oculatus) at its northern range edge: implications for conservation. Conservation Genetics. DOI: 10.1007/s10592-015-0708-2.

Grande, L. 2010. An empirical synthetic pattern study of gars (Lepisosteiformes) and closely related species, based mostly on skeletal anatomy. The 
resurrection of Holostei. Copeia 2010(American Society of Ichthyologists and Herpetologists Special Publication 6): 778.

Heibo, E., C. Magnhagen, and L. A. Vollestad. 2005. Latitudinal variation in life-history traits in Eurasian Perch. Ecology 86:3377-3386.

Helfman, G. S. 2007. Fish conservation. Island Press, Washington, D.C.

Hocutt, C. H., and E. O. Wiley. 1986. The zoogeography of North American freshwater fishes. Wiley, New York.

Holt, R. 1973. Age and growth, length-weight relationship, condition coefficient, and feeding habits of Spotted Gar, Lepisosteus oculatus (Winchell), within the Kentucky waters of Kentucky Reservoir. Master's thesis. Murray State University, Murray, Kentucky.

Hooper, D. U., F. S. Chapin III, J. J. Ewel, A. Hector, P. Inchausti, S. Lavorel, J. H. Lawton, D. M. Lodge, M. Loreau, S. Naeem, B. Schmid, H. Setala, A. J. Symstad, J. Vandermeer, and D. A. Wardle. 2005. Effects of biodiversity on ecosystem functioning: a consensus of current knowledge. Ecological Monographs 75:3-35.

Hubbs, C. L., K. F. Lagler, and G. R. Smith. 2004. Fishes of the Great Lakes region, revised edition. University of Michigan Press, Ann Arbor.

Hurst, T. P. 2007. Causes and consequences of winter mortality in fishes. Journal of Fish Biology 71:315-345.

JMP. 2001. JMP, version 4. SAS Institute, Cary, North Carolina.

Johannesson, K., and C. Andre. 2006. Life on the margin: genetic isolation and diversity loss in a peripheral marine ecosystem, the Baltic Sea. Molecular Ecology 15:2013-2029.

Jones, B., C. Gliddon, and J. E. G. Good. 2001. The conservation of variation in geographically peripheral populations: Lloydia serotina (Liliaceae) in Britain. Biological Conservation 101:147-156.

Kyle, C. J., and C. Strobeck. 2002. Connectivity of peripheral and core populations of North American wolverines. Journal of Mammalogy 83:1141-1150.

Kynard, B. 1997. Life history, latitudinal patterns, and status of the Shortnose Sturgeon, Acipenser brevirostrum. Environmental Biology of Fishes 48:319-334.

Lammi, A., P. Siikamaki, and K. Mustajarvi. 2001. Genetic diversity, population size, and fitness in central and peripheral populations of a rare plant Lychnis viscaria. Conservation Biology 13:1069-1078.

Lande, R. 1993. Risks of population extinction from demographic and environmental stochasticity and random catastrophes. American Naturalist 142:911-927.

Lardies, M. A., L. D. Bacigalupe, and F. Bozinovic. 2004. Testing the metabolic cold adaptation hypothesis: an intraspecific latitudinal comparison in the common wood louse. Evolutionary Ecology Research 6:567-578.

Latta, W. C. 2003. Distribution and abundance of Michigan fishes collected 1993-2001. Michigan Department of Natural Resources, Fisheries Research Report, Ann Arbor.

Lee, H., D. DeAngelis, and H. Koh. 1998. Modeling spatial distribution of the unionid mussels and the core-satellite hypothesis. Water, Science, and Technology 38:73-79.

Lesica, P., and F. W. Allendorf. 1995. When are peripheral populations valuable for conservation? Conservation Biology 9:753-760.

Luck, G. W., G. C. Daily, and P. R. Ehrlich. 2003. Population diversity and ecosystem services. Trends in Ecology and Evolution 18:331-336.

Mach, M. E., E. J. Sbrocco, L. A. Hice, T. A. Duffy, D. O. Conover, and P. H. Barber. 2011. Regional differentiation and post-glacial expansion of the Atlantic Silverside, Menidia menidia, an annual fish with high dispersal potential. Marine Biology 158:515-530.

Marcil, J., D. P. Swain, and J. A. Hutchings. 2006. Genetic and environmental components of phenotypic variation in body shape among populations of Atlantic Cod (Gadus morhua L.). Biological Journal of the Linnean Society 88:351-365.

Mendoza Alfaro, R., C. A. Gonzales, and A. M. Ferrara. 2008. Gar biology and culture: status and prospects. Aquaculture Research 39:748-763.

Michigan Department of Natural Resources. 2005. Species of greatest conservation need. Michigan's wildlife action plan. State of Michigan, Lansing.
Mittelbach, G. G., and L. Persson. 1998. The ontogeny of piscivory and its ecological consequences. Canadian Journal of Fisheries and Aquatic Sciences 55:1454-1465.

Munch, S. B., M. Mangel, and D. O. Conover. 2003. Quantifying natural selection on body size from field data: winter mortality in Menidia menidia. Ecology 84:2168-2177.

NOAA (National Oceanic and Atmospheric Administration) National Climate Data Center. 2011. U.S. climate normals 1971-2000. Available: http://cdo. ncdc.noaa.gov/cgi-bin/climatenormals/climatenormals.pl. (February 2011).

Page, L. M., and B. M. Burr. 1991. A field guide to freshwater fishes. Houghton Mifflin, Boston.

Petchey, O. L., A. L. Downing, G. G. Mittelbach, L. Persson, C. F. Steiner, P. H. Warren, and G. Woodward. 2004. Species loss and structure and functioning of multitrophic aquatic systems. Oikos 104:467-478.

Power, M., and R. S. McKinley. 1997. Latitudinal variation in Lake Sturgeon size as related to the thermal opportunity for growth. Transactions of the American Fisheries Society 126:549-558.

Present, T. M., and D. O. Conover. 1992. Physiological basis of latitudinal growth differences in Menidia menidia: variation in consumption or efficiency? Functional Ecology 6:23-31.

Redmond, L. C. 1964. Ecology of the Spotted Gar (Lepisosteus oculatus Winchell) in southeastern Missouri. Master's thesis. University of Missouri, Columbia.

Scarnecchia, D. L. 1992. A reappraisal of gars and bowfins in fishery management. Fisheries 17(5):6-12.

Schultz, E. T., K. E. Reynolds, and D. O. Conover. 1996. Countergradient variation in growth among newly hatched Fundulus heteroclitus: geographic differences revealed by common-environment experiments. Functional Ecology 10:366-374.

Scudder, G. G. E. 1989. The adaptive significance of marginal populations: a general perspective. Canadian Special Publication of Fisheries and Aquatic Sciences 105:180-185.

Simon, T. P., and E. J. Tyberghein. 1991. Contributions to the early life history of the Spotted Gar, Lepisosteus oculatus Winchell, from Hatchet Creek, Alabama. Transactions of the Kentucky Academy of Science 52:124-131.

Simon, T. P., and R. Wallus.1989. Contributions to the early life histories of gar (Actinopterygii: Lepisosteidae) in the Ohio and Tennessee River basins with emphasis on larval development. Transactions of the Kentucky Academy of Science 50:59-71.

Slaughter, J. E. IV, R. A. Wright, and D. R. DeVries. 2004. The effects of age0 body size and the predictive ability of a Largemouth Bass bioenergetics model. Transactions of the American Fisheries Society 133:279-291.

Slaughter, J. E. IV, R. A. Wright, and D. R. DeVries. 2008. Latitudinal influence on first-year growth and survival of Largemouth Bass. North American Journal of Fisheries Management 28:993-1000.

Snedden, G. A., W. E. Kelso, and D. A. Rutherford. 1999. Diel and seasonal patterns of Spotted Gar movement and habitat use in the lower Atchafalaya River basin, Louisiana. Transactions of the American Fisheries Society 128:144-154.

Stearns, S. C., and J. C. Koella. 1986. The evolution of phenotypic plasticity in life-history traits: predictions of reaction norms for age and size at maturity. Evolution 40:893-913.

Suttkus, R. D. 1963. Order Lepisostei. Pages 61-88 in H. B. Bigelow, C. M. Breeder, Y. H. Olsen, D. M. Cohen, W. C. Schroeder, G. W. Mead, L. P. Schultz, D. Merriman, and J. Tee-Van, editors. Fishes of the western North Atlantic; part three, soft-rayed fishes. Yale University, Memoir Sears Foundation for Marine Research 1, New Haven, Connecticut.

Trautman, M. B. 1981. The Fishes of Ohio, revised edition. Ohio State University Press, Columbus.

United Nations. 1992. Convention on biological diversity. United Nations, New York. Available: http://www.cbd.int/. (June 2015).

USEPA (U.S. Environmental Protection Agency). 2007. Biological indicators of watershed health. Available: www.epa.gov/bioiweb1/html/fish_indicators. html. (August 2008). 
Wiley, E. O. 1976. The phylogeny and biogeography of fossil and recent gars (Actinopterygii: Lepisosteidae). University of Kansas Museum of Natural History Miscellaneous Publication 64.

Wilson, B. S., and D. E. Cooke. 2004. Latitudinal variation in rates of overwinter mortality in the lizard Uta stansburiana. Ecology 85:34063417.

Wisely, S. M., S. W. Buskirk, G. A. Russell, K. B. Aubry, and W. J. Zielinski. 2004. Genetic diversity and structure of the fisher (Martes pennanti) in a peninsular and peripheral metapopulation. Journal of Mammalogy 85:640648.
Wright, J. J., S. R. David, and T. J. Near. 2012. Gene trees, species trees, and morphology converge on a similar phylogeny of living gars (Actinopterygii: Holostei: Lepisosteidae), an ancient clade of ray-finned fishes. Molecular Phylogenetics and Evolution 63:848-856.

Yakimowski, S. B., and C. G. Eckert. 2007. Threatened peripheral populations in context: geographical variation in population frequency and size and sexual reproduction in a clonal woody shrub. Conservation Biology 21:811-822.

Yamahira, K., and D. O. Conover. 2002. Intra- vs. interspecific latitudinal variation in growth: adaptation to temperature or seasonality? Ecology $83: 1252-1262$. 